\title{
La implementación de las decisiones de la Corte Interamericana de Derechos Humanos: comentarios en torno al caso "Corte Primera de lo Contencioso Administrativo"
}

Este comentario, junto a los documentos que analiza, está disponible en www.anuariocdh.uchile.cl

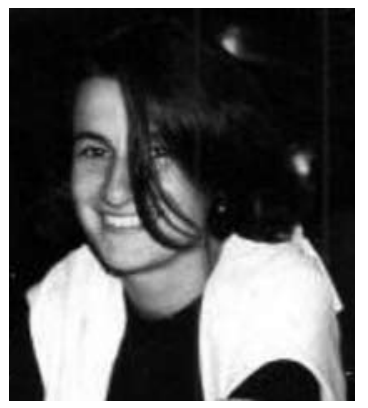

\section{Liliana Tojo}

Abogada de la Universidad Nacional de Buenos Aires. Directora del Programa para Bolivia y Cono Sur del Centro por la Justicia y el Derecho Internacional (CEJIL). Profesora de la Maestría de Derechos Humanos de la Universidad Nacional de La Plata (Argentina).

Itojo@cejil.org

\section{RESUMEN}

A través del análisis de la sentencia de la Corte Interamericana de Derechos Humanos en el Caso Aspitz Barbera y otros vs. Venezuela y la posterior decisión de la Sala Constitucional del Tribunal Supremo de Justicia de la República Bolivariana de Venezuela, el artículo muestra algunas de las tensiones que se detectan al tiempo de implementar a nivel nacional las decisiones de los órganos internacionales de protección de los derechos humanos.

En agosto de 2008 la Corte Interamericana de Derechos Humanos emitió una sentencia en el Caso Aspitz Barbera y otros Vs. Venezuela, también conocido como "Corte Primera de lo Contencioso Administrativo" ${ }^{\prime 1}$. La decisión del Tribunal internacional provocó una notoria respuesta del Estado venezolano que replanteó las discusiones en torno a la implementación de las decisiones de los órganos del sistema interamericano de derechos humanos y a pensar -de alguna forma- los límites de la protección internacional.

El caso, presentado dos años antes por la Comisión Interamericana de Derechos Humanos, denunciaba las violaciones a la Convención Americana de Derechos Humanos contenidas en los procedimientos de destitución de dos jueces y una jueza de la Corte Primera de lo Contencioso Administrativo. De acuerdo con la Ley Orgánica de la Corte Suprema de Justicia, la Corte Primera tenía competencia para conocer del control de todos los actos administrativos del poder público, a excepción de aquellos emanados del Presidente de la República y sus ministros, siendo sus sentencias recurribles sólo ante el Tribunal Supremo de Justicia².

\footnotetext{
El texto íntegro de la sentencia puede ser consultado en http://www.corteidh.or.cr/docs/casos/articulos/seriec_182_esp.pdf

2 Corte IDH, Caso Aspitz Barbera y otros ("Corte Primera de lo Contencioso Administrativo") Vs. Venezuela. Sentencia de 5 de agosto de 2008. Excepción preliminar, Fondo, Reparaciones y Costas. Párrs. 30 y 31.
} 
Los magistrados en cuestión -Juan Carlos Apitz Barbera, Perkins Rocha Contrareas y Ana María Ruggeri Cova- habían sido designados en sus cargos en el año 2000, con carácter provisorio hasta tanto se sustanciaran los correspondientes concursos para acceder a la titularidad. En ejercicio de su magistratura la Corte Primera, acogió un amparo presentado contra un acto administrativo de un funcionario del Registro Público ${ }^{3}$ que se negaba a protocolizar una propiedad. Un año después el caso llegó a la Sala Constitucional del Tribunal Supremo de Justicia que resolvió a favor de la nulidad de la decisión de la Corte Primera por "grave error jurídico de carácter inexcusable" y considera la decisión como una irregularidad sumamente grave reportándola a la Inspectoría General de Tribunales ${ }^{4}$.

Esta Inspectoría era el órgano auxiliar de la Comisión General de Funcionamiento y Reestructuración del Sistema Judicial ${ }^{5}$. Ambos organismos tenían a su cargo la competencia disciplinaria judicial hasta tanto fuera aprobada la legislación que regulara los procesos y tribunales disciplinarios para el Poder Judicial, tal como lo había previsto la reforma constitucional del año 1999. La Inspectoría como la Comisión General habían sido ratificadas por la ley orgánica del Tribunal Superior de Justicia, aunque sujetas a la creación de los tribunales disciplinarios. La Comisión resolvió en octubre de 2003 a favor de la destitución de los jueces.

\section{La Sentencia de la Corte IDH}

La Corte Interamericana de Derechos Humanos pudo avanzar en el análisis de varias cuestiones vinculadas con la estabilidad e independencia de los miembros del Poder Judicial. En particular abordó la cuestión de si el procedimiento de destitución al que habían sido sometidos los dos jueces y la jueza -que tenían nombramientos provisorios- se ajustaba a las garantías de debido proceso consagradas por la Convención Americana sobre Derechos Humanos.

El tema ponía bajo el escrutinio de la jurisdicción internacional una de las cuestiones centrales para la calidad de la administración de justicia y un punto extremadamente relevante de la agenda de derechos humanos no sólo en Venezuela, sino en buena parte del continente americano ${ }^{6}$.

En su decisión del caso la Corte Interamericana rechazó por falta de pruebas la alegación sobre falta de independencia en general del Poder Judicial venezolano, pero analizó si el órgano que destituyó a los jueces había ofrecido garantías suficientes para que pudiera ser considerado un tribunal independiente. Al respecto concluyó que la prolongación en el tiempo -desde 1999_7 de un régimen de transición -que según la Constitución no debía prolongarse por más de un año-, sumado a la omisión legislativa en la adopción de un Código de Ética, redundó en que las víctimas fueran juzgadas por un órgano excepcional que carecía de estabilidad definida y cuyos miembros podían ser nombrados o removidos sin procedimientos previamente establecidos, a sola discreción del Tribunal Superior de Justicia, características que no alcanzaban a satisfacer las garantías de independencia suficientes que exige el derecho internacional.

\footnotetext{
Se trataba del Registrador Subalterno del Primer Circuito de Registro Público del Municipio de Baruta del Estado Miranda, párr. 32 de la sentencia.

4 Corte IDH, Caso Apitz Barbera y otros ("Corte Primera de lo Contencioso Administrativo") Vs. Venezuela. Párr. 35.

5 En adelante, también nos referiremos a ella como "la Comisión General".

6 Para un análisis general del tema puede verse -entre otros- el Informe del Relator Especial sobre Independencia de Jueces y Abogados, A/HRC/11/41 del 24 de marzo de 2009, disponible en: http://www2.ohchr.org/english/bodies/hrcouncil/ docs/11session/A.HRC.11.41_en.pdf

7 Ese es el año de la reforma constitucional en Venezuela.
} 
Adicionalmente, consideró que aun cuando Venezuela había ofrecido a los jueces y la jueza un proceso previo a cargo de un organismo con competencia general para conocer de todos los procesos disciplinarios contra miembros del Poder Judicial, el hecho de que sus integrantes no pudieran ser recusados violentaba el derecho a un tribunal imparcial. Finalmente, la Corte Interamericana concluyó que la decisión carecía de la debida motivación ${ }^{8}$, lo que en este caso suponía como mínimo el análisis de la idoneidad de los jueces y la jueza para el ejercicio del cargo, las razones sobre la gravedad de la falta que justificaría la decisión de la destitución y la proporcionalidad entre ellas y la sanción adoptada -en particular aquellas que permitieran distinguir entre una "diferencia razonable de interpretaciones jurídicas" y un "error judicial inexcusable" que afectara la idoneidad de los jueces, así como la proporcionalidad de la decisión adoptada ${ }^{9}$.

En función de estas consideraciones la Corte Interamericana estableció que se habían cometido violaciones a la Convención Americana y ordenó las siguientes medidas reparatorias:

i) El pago de indemnizaciones en concepto de daño material e inmaterial;

ii) El reintegro de las víctimas al Poder Judicial en un cargo con remuneraciones, beneficios sociales y rango equiparable al que les correspondería al momento de la sentencia de no haber sido destituidos; o una indemnización si el Estado no pudiese reincorporarlas por motivos fundados ajenos a la voluntad de las víctimas;

iii) La publicación de la sentencia en el Diario Oficial y en otro de circulación nacional;

iv) La adecuación de la legislación interna necesaria para garantizar la imparcialidad del órgano disciplinario, permitiendo por ejemplo, la recusación de sus miembros, y la independencia regulando el proceso de nombramiento de sus integrantes y su estabilidad en el cargo.

\section{La reacción del Poder Judicial venezolano: la decisión de la Sala Constitucional del Tribunal Supremo de Justicia}

Cuatro meses después de la decisión de la Corte Interamericana de Derechos Humanos el Estado venezolano -a través de la Procuraduría General de la República- presentó una acción de control de la constitucionalidad ante el Tribunal Supremo de Justicia, solicitando la interpretación del fallo dictado por la Corte Interamericana de Derechos Humanos. En palabras de la propia Sala Constitucional del Tribunal el objeto de la presentación "[...]versa sobre el alcance e inteligencia de la ejecución de una decisión dictada por un organismo internacional con base en un tratado de jerarquía constitucional, ante la presunta antinomia entre esta Convención Internacional y la Constitución Nacional[... $]^{\prime 10}$.

Los argumentos de esta decisión parten de destacar la naturaleza coadyuvante o complementaria -tal como está expresado en el Preámbulo de la Convención Americana- de la protección internacional, de la que se desprende que no puede excluir o desconocer el ordenamiento constitucional interno. En esta línea destaca que el texto constitucional en su artículo $23^{11}$ no otorga

8 Corte IDH, Caso Aspitz Barbera y otros ("Corte Primera de lo Contencioso Administrativo") Vs. Venezuela. Párr. 78.

9 Corte IDH, Caso Aspitz Barbera y otros ("Corte Primera de lo Contencioso Administrativo") Vs. Venezuela. Párr. 90.

10 Tribunal Supremo de Justicia. Sala Constitucional. República Bolivariana de Venezuela. Expediente No 08-1572. Sentencia de 18 de diciembre de 2008.

11 Constitución de la República Bolivariana de Venezuela. Artículo 23. "Los tratados, pactos y convenciones relativos a derechos humanos, suscritos y ratificados por Venezuela, tienen jerarquía constitucional y prevalecen en el orden interno, en la medida en que contengan normas sobre su goce y ejercicio más favorables a las establecidas por esta Constitución y la ley de la República, y son de aplicación inmediata y directa por los tribunales y demás órganos del Poder Público". 
a los tratados internacionales sobre derechos humanos rango "supraconstitucional", por lo que en caso de antinomia entre éstos y la Constitución el Poder Judicial debe determinar cuál sería la aplicable.

A partir de esta posición, la Sala Constitucional cuestiona la decisión de la Corte Interamericana de Derechos Humanos, indicando que frente a una supuesta -como la califica la propia sentencia- violación de derechos, dicta pautas de carácter obligatorio sobre gobierno y administración del Poder Judicial, avanzando sobre competencias exclusivas del Tribunal Supremo de Justicia y le da directrices al Poder Legislativo para que dicte normas vinculadas con la carrera judicial y la estabilidad de los jueces.

En la lógica del Poder Judicial venezolano, la Corte Interamericana avanza sobre el orden jurídico nacional al pretender la reincorporación de los jueces a los que considera legítimamente destituidos, y cuestionar el sistema disciplinario vigente.

En consecuencia, la decisión del máximo Tribunal venezolano se inclina por declarar la inejecutabilidad del fallo de la Corte Interamericana y solicita al Poder Ejecutivo la denuncia de la Convención Americana en los términos previstos en su artículo $78^{12}$.

El impacto a nivel local que produjo la sentencia de la Corte Interamericana sirve para actualizar algunas preguntas respecto de la forma en que opera la relación entre el derecho internacional de los derechos humanos y el Poder Judicial local. Por un lado, el desarrollo y la consolidación del derecho internacional de los derechos humanos y dentro de este ámbito del derecho interamericano, puso a disposición de los jueces un cuerpo normativo que amplió la base con la que pueden trabajar para la protección de derechos. Al mismo tiempo, limitó su actuación porque - de alguna manera- integró los sistemas de justicia locales dentro del sistema internacional de protección de los derechos humanos.

Es evidente que el ejercicio voluntario de soberanía representado por la decisión de un Estado de convertirse en Parte de un tratado internacional de derechos humanos representa algunos costos; el alcance de los mismos estará determinado por el grado de injerencia que los Estados estén dispuestos a aceptar por parte del sistema del que han decidido formar parte voluntariamente.

Es posible identificar diversas formas en la que podrían administrarse estas tensiones. Una respuesta puede pasar por una amplia recepción de los tratados de derechos internacionales por parte del sistema constitucional. Argentina puede constituir un ejemplo en este sentido, no sólo por la cláusula de incorporación de los tratados a la Constitución Nacional ${ }^{13}$, sino también por el reconocimiento por vía de la jurisprudencia de su carácter operativo ${ }^{14}$, así como la consagración del principio de que la jurisprudencia de los órganos internacionales que aplican estos tratados

12 Convención Americana de Derechos Humanos. Artículo 78. “1. Los Estados partes podrán denunciar esta Convención después de la expiración de un plazo de cinco años a partir de la fecha de entrar en vigor de la misma y mediante un preaviso de un año, notificando al Secretario General de la Organización, quien debe informar a las otras partes. 2. Dicha denuncia no tendrá por efecto desligar al Estado Parte interesado de las obligaciones contenidas en esta Convención en lo que concierne a todo hecho que, pudiendo constituir una violación de esas obligaciones, haya sido cumplido por él anteriormente a la fecha en la cual la denuncia produce efecto".

13 Me refiero al artículo 75 (22) de la Constitución de la Nación Argentina.

14 Para un análisis de las decisiones de la Corte Suprema de Justicia de la Nación en Argentina respecto de este tema puede consultarse DI CORLETO, Julieta. El reconocimiento de las decisiones de la Comisión y la Corte Interamericana en las Sentencias de la Corte Suprema de Justicia Argentina. En: KRSTICEVIC, Viviana y TOJO Liliana (Coords). Implementación de las Decisiones del Sistema Interamericano de Derechos Humanos. Jurisprudencia, normativa y experiencias nacionales. CEJIL. Buenos Aires. 2007. 
-como sería el caso de la Corte Interamericana de Derechos Humanos- constituye una interpretación autorizada y por tanto una guía para su aplicación en la jurisdicción local ${ }^{15}$.

Otra variante en esta misma línea puede construirse a partir del uso de la noción de "bloque de constitucionalidad". Esta herramienta permite enriquecer los debates sobre la justicia constitucional al trabajar con la idea de que una Constitución puede tener mayor densidad y extensión que la que resultaría de la lectura simple de su articulado $^{16}$, y que se integraría también por los tratados internacionales de derechos humanos. De este modo, la propia Constitución comparte su calidad con otros textos normativos.

Sin duda la resolución del Tribunal venezolano representa una posición alternativa a las antes referidas que se sintetizaría en que los tribunales nacionales son los últimos intérpretes y los tratados de derechos humanos -y lo que sus órganos de aplicación dicen respecto de ellos- no pueden aplicarse si son contrarias a la legalidad, vista ésta desde la perspectiva nacional.

Mas allá de la posición general de la República Bolivariana de Venezuela sobre política internacional y la forma como ésta se concretiza en relación con los sistemas de protección de los derechos humanos ${ }^{17}$, la reacción del Poder Judicial frente a la decisión de la Corte Interamericana de Derechos Humanos en el caso Aspitz Barbera recrea el debate sobre la implementación de tales decisiones planteándolo desde la perspectiva de la reacción del judicial.

Algunos autores -como Lusverti- describen la tendencia de la jurisprudencia constitucional venezolana en este punto afirmando que "no se trata de una tendencia casual sino que más bien se trata de una línea jurisprudencial constitucional pacífica y constante en el foro venezolano, que tiende a endurecerse conforme debilita la supervisión de los sistemas internacionales de protección"18.

\section{Conclusiones}

Frente a determinadas violaciones del derecho internacional sufridas por alguno de los jueces de la Corte Primera de lo Contencioso Administrativo, la Corte Interamericana de Derechos humanos estableció medidas de reparación concretas y la ejecución de las mismas se vio obstaculizada por una decisión del Poder Judicial que declaró "inejecutable" las reparaciones ordenadas.

Aun cuando el texto constitucional venezolano ofrece un marco normativo que favorecería -en principio- la ejecución de las decisiones emanadas de una jurisdicción internacional ${ }^{19}$, la interpretación que de las mismas hacen los poderes del Estado limita su potencial. Debería -a partir de

15 ABRAMOVICH, Víctor. Las normas internacionales en la práctica constitucional argentina. Revista CEIIL. Debates sobre Derechos Humanos y el Sistema Interamericano, № 1. Diciembre de 2005. p. 85.

16 UPRIMNY, Rodrigo. El bloque de constitucionalidad en Colombia. Un análisis jurisprudencia y un ensayo de sistematización doctrinal. En: Compilación de Jurisprudencia y doctrina nacional e internacional. Bogotá: Oficina Alto Comisionado de NU para los derechos humanos. Diciembre de 2005. Disponible en http://dejusticia.org/interna. php?id_tipo_publicacion=5?id_tipo_publicacion=5\&id_publicacion=72. En este mismo artículo el autor marca las potencialidades y riesgos que el uso de la noción de "bloque de constitucionalidad" trae consigo.

17 A modo de ejemplo puede verse el texto del Discurso del Estado venezolano en la Audiencia realizada en la Comisión Interamericana de Derechos Humanos. OEA, Washington D.C., 24 de marzo de 2009, disponible en: http://www. venezuela-oas.org/GermanSaltronCIDH24-03-09.htm

18 LUSVERTI, Carlos F. El derecho internacional de los derechos humanos y los tribunales nacionales: el caso de Venezuela. Revista CEJIL. Debates sobre derechos humanos y el Sistema Interamericano, № 1. Diciembre de 2005.

19 Además del artículo 23 citado anteriormente, cabe destacar el texto del artículo 31 de la Constitución de la República Bolivariana deVenezuela: "Toda persona tiene derecho, en los términos establecidos por los tratados, pactos y convenciones sobre derechos humanos ratificados por la República, a dirigir peticiones o quejas ante los órganos internacionales creados para tales fines, con el objeto de solicitar el amparo a sus derechos humanos. El Estado adoptará, conforme a 
este caso- reflexionarse más profundamente sobre la necesidad de hacer -en forma paralela- un uso más efectivo los mecanismos políticos regionales para favorecer un mejor funcionamiento de la garantía colectiva frente al cumplimiento de las decisiones de los órganos internacionales, pues ésta es una responsabilidad que -con distintos matices- alcanza tanto a los órganos como a los otros actores relevantes del sistema regional. 